\title{
Improved design of hammerhead ribozyme for selective digestion of target RNA through recognition of site-specific adenosine-to-inosine RNA editing
}

\author{
MASATORA FUKUDA, ${ }^{1}$ KEI KURIHARA, SHOTA YAMAGUCHI, YUI OYAMA, and MASANOBU DESHIMARU \\ Department of Chemistry, Faculty of Science, Fukuoka University, Nanakuma, Jonan-ku, Fukuoka 814-0180, Japan
}

\begin{abstract}
Adenosine-to-inosine (A-to-I) RNA editing is an endogenous regulatory mechanism involved in various biological processes. Site-specific, editing-state-dependent degradation of target RNA may be a powerful tool both for analyzing the mechanism of RNA editing and for regulating biological processes. Previously, we designed an artificial hammerhead ribozyme (HHR) for selective, site-specific RNA cleavage dependent on the A-to-I RNA editing state. In the present work, we developed an improved strategy for constructing a trans-acting HHR that specifically cleaves target editing sites in the adenosine but not the inosine state. Specificity for unedited sites was achieved by utilizing a sequence encoding the intrinsic cleavage specificity of a natural HHR. We used in vitro selection methods in an HHR library to select for an extended HHR containing a tertiary stabilization motif that facilitates HHR folding into an active conformation. By using this method, we successfully constructed highly active HHRs with unedited-specific cleavage. Moreover, using HHR cleavage followed by direct sequencing, we demonstrated that this ribozyme could cleave serotonin $2 \mathrm{C}$ receptor (HTR2C) mRNA extracted from mouse brain, depending on the site-specific editing state. This unedited-specific cleavage also enabled us to analyze the effect of editing state at the $E$ and $C$ sites on editing at other sites by using direct sequencing for the simultaneous quantification of the editing ratio at multiple sites. Our approach has the potential to elucidate the mechanism underlying the interdependencies of different editing states in substrate RNA with multiple editing sites.
\end{abstract}

Keywords: A-to-I RNA editing; hammerhead ribozyme; in vitro selection

\section{INTRODUCTION}

Substitutional RNA editing is a mechanism that alters genomic information after transcription (Maas and Rich 2000; Bass 2002; Farajollahi and Maas 2010). A-to-I RNA editing, which converts specific sites of adenosine (A) to inosine (I), is the most common event in Metazoans; for review of their known biological functions, see Nishikura (2010); these functions include alterations in the amino acid sequence because inosine is decoded as guanosine (Higuchi et al. 1993; Burns et al. 1997; Rueter et al. 1999), regulation of alternative splicing (Rueter et al. 1999; Bratt and Ohman 2003; Schoft et al. 2007), changes in RNA stability and RNA localization (Prasanth et al. 2005; Chen et al. 2008), protection against viral RNA by hyper-editing (Gelinas et al. 2011), and modulation of the maturation and specificity of miRNA (Yang et al. 2006; Kawahara et al. 2007; Vesely et al. 2012). Recently, it has also been reported that A-to-I RNA editing is related to embryological development (Higuchi et al. 2000; Wang

\footnotetext{
${ }^{1}$ Corresponding author

E-mail masatora@fukuoka-u.ac.jp

Article published online ahead of print. Article and publication date are at http://www.rnajournal.org/cgi/doi/10.1261/rna.041202.113.
}

et al. 2000) and differentiation (Osenberg et al. 2010). Although biological and biochemical data, in addition to RNA editome analysis from high-throughput RNA sequencing data (Park et al. 2012; Peng et al. 2012), have indicated that A-to-I RNA editing is related to the regulation of various biological processes, many of the detailed biological functions of such editing are still unclear.

The most studied examples of A-to-I editing occurring in coding regions are the glutamate receptor subunit $\mathrm{B}$ (GRIA2) (Sommer et al. 1991) and the serotonin 2C receptor (HTR2C) (Burns et al. 1997); these editing processes are essential for the proper functioning of the nervous system (Hood and Emeson 2012). In contrast to GRIA2, HTR2C pre-mRNA is edited at the proximal five adenosines, which have been named the A, B, E, C, and D sites, in exon V (Fig. 1B). Therefore, combinatorial editing at these sites can lead to 24 different isoforms, with various receptor functions of

\footnotetext{
(c) 2014 Fukuda et al. This article is distributed exclusively by the RNA Society for the first 12 months after the full-issue publication date (see http://rnajournal.cshlp.org/site/misc/terms.xhtml). After 12 months, it is available under a Creative Commons License (Attribution-NonCommercial 3.0 Unported), as described at http://creativecommons.org/licenses/by-nc/ $3.0 \%$
} 

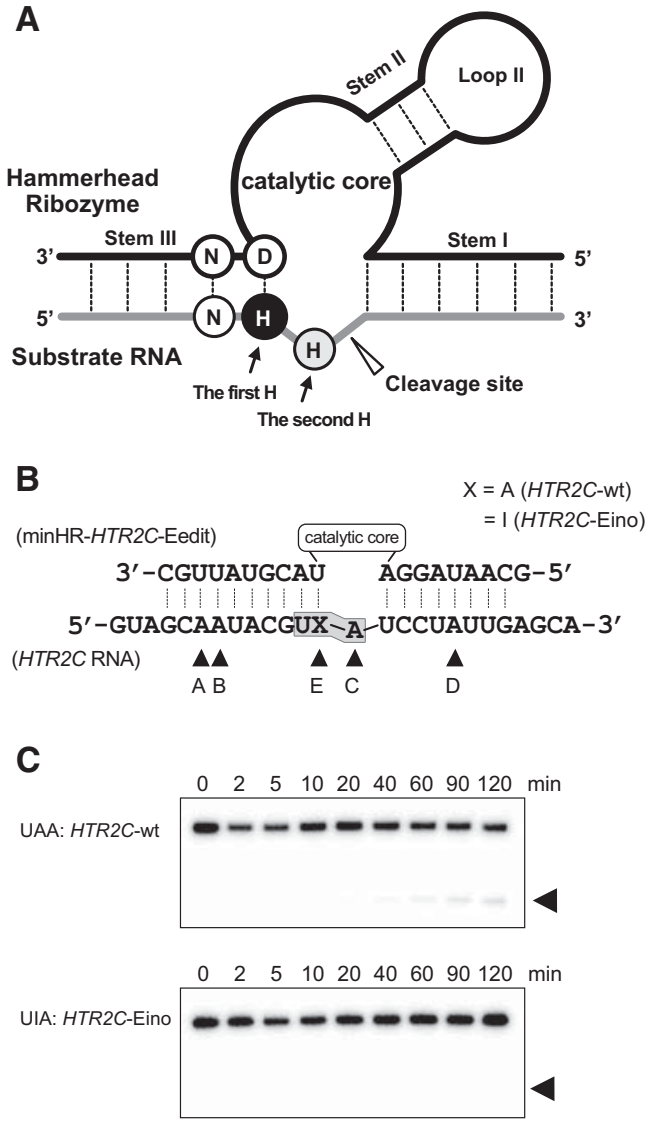

FIGURE 1. Construction of the trans-acting HHR designed utilizing the $\mathrm{NHH}$ preference for specific target cleavage depending on the site-specific A-to-I unedited state. (A) Schematic representation of minimal-HHR (minHHR) with NHH cleavage preference. HHR and substrate RNA are shown as black and gray lines, respectively, and dashed lines indicate the base-pair interactions. A minHHR has three stems: Stem I and stem III are in the hybridizing arms for recognizing the target sequence with Watson-Crick base-pairing, and stem-loop II is in the catalytic core. On the substrate RNA, black and gray circles denote the first and second $\mathrm{H}$ positions, respectively. The nucleotide denoted as $\mathrm{D}$ ( $\mathrm{A}$ or $\mathrm{G}$ or $\mathrm{U}$, except for $\mathrm{C}$ ) forms a base pair with the first $\mathrm{H}$. (B) HHR design utilizing the first $\mathrm{H}$ position of $\mathrm{NHH}$ specificity for specific HTR2C RNA cleavage when the E site is unedited. Sequences of ribozyme (HR-HTR2C-Eedit) and a part of the synthetic HTR2C RNA fragment are shown. The nucleotides corresponding to the $\mathrm{NHH}$ triplet are indicated in gray. The editing sites of adenosines on the HTR2C RNA are indicated as black arrowheads, in which only the $\mathrm{E}$ site is represented as X (A or I). HR-HTR2C-Eedit was designed to set the E site to the second $\mathrm{H}$ position for unedited-specific cleavage. The sequence of the catalytic core is $5^{\prime}$-CUGAUGAGGCCGAAAGGCCGAA-3'. Substrate RNAs that are unedited $(\mathrm{X}=\mathrm{A})$ and edited $(\mathrm{X}=\mathrm{I})$ at the $\mathrm{E}$ site are denoted as HTR2C-wt and HTR2C-Eino, respectively. (C) Analysis of A-to-I unedited-specific cleavage by HR-HTR2C-Eedit using denaturing PAGE (15\%). The cleavage reaction was performed with HTR2Cwt (upper) and HTR2C-Eino (lower) in the presence of an excess of HR-HTR2C-Eedit at $37^{\circ} \mathrm{C}$ for different times. The positions of the resulting $5^{\prime}$-cleavage products $(\mathrm{P})$ are indicated.

G-protein coupling and serotonin affinity (Werry et al. 2008). On the other hand, the five editing sites on HTR2C premRNA are closely spaced, and it is believed that editing at one site would correlate with further editing at other site
(Du et al. 2006; Enstero et al. 2009; Carmel et al. 2012). Although the A-to-I RNA editing pattern that is formed by these editing sites on HTR2C mRNA can regulate receptor function and the subsequent signal transmission, the detailed mechanism of interdependencies between the editing states remains unclear.

A method for specific target RNA cleavage depending on the A-to-I RNA editing state would be a useful tool for analyzing the functions of individual editing processes. The hammerhead ribozyme (HHR) is chosen for this purpose because of its target RNA cleavage activity. Minimal transcleaving HHRs engineered by modifying natural HHRs (Uhlenbeck 1987; Haseloff and Gerlach 1988) have been used for specific-target RNA cleavage in vitro and in vivo (Goodchild 2002; Citti and Rainaldi 2005; Tedeschi et al. 2009). Since minimal-HHR (minHHR) consists of a conserved central catalytic core and two hybridizing arms for recognizing the target sequence, a target-specific HHR can be simply designed by altering the sequences of the hybridizing arms against the target RNA sequence according to WatsonCrick base-pairing rules. Generally, an HHR can cleave target RNA with an NHH triplet at the phosphodiester bond at $3^{\prime}$ to the second $\mathrm{H}$, where $\mathrm{N}$ is any nucleotide, and $\mathrm{H}$ can be either A, C, or U, but not G (Fig. 1A; Kore et al. 1998). Hence, this intrinsic cleavage specificity for NHH triplets has been utilized for mutation-specific RNA cleavage (Scherr et al. 1997; Lewin et al. 1998; Dawson and Marini 2000). Due to the similarity of the chemical structure of guanosine and inosine, it was considered that both $\mathrm{H}$ positions could be utilized for A-to-I RNA editing recognition.

In contrast to minHHR, most of the natural HHRs form tertiary interactions that stabilize their catalytically active structure. For instance, the SMal hammerhead ribozyme from Schistosoma mansoni (Ferbeyre et al. 1998; VazquezTello et al. 2002) is stabilized by tertiary interactions between loop II and a symmetrical internal bulge in stem I. These cisacting HHRs with tertiary stabilizing motifs (TSMs) showed high cleavage activity even at low $\mathrm{Mg}^{2+}$ concentrations similar to physiological conditions (De la Peña et al. 2003; Khvorova et al. 2003; Penedo et al. 2004). Trans-acting HHRs with a TSM, called extended HHRs (exHHRs), have also been developed by sequence design using natural TSMs from peach latent mosaic viroid (PLMVd) and eggplant latent viroid (ELVd) ribozyme (Carbonell et al. 2011). Additionally, an artificial TSM has been generated by a combinatorial method using Systematic Evolution of Ligands by EXponential enrichment (SELEX) so as to efficiently cleave target RNA at the physiological $\mathrm{Mg}^{2+}$ concentration (Saksmerprome et al. 2004).

We have previously reported a method for constructing a trans-acting HHR for target RNA cleavage based on A-to-I RNA editing (Fukuda et al. 2012). In this strategy, editing recognition ability was introduced into the canonical minHHR by substituting the recognition nucleotide, in which basepairing is highly sensitive to cleavage activity (Werner and 
Uhlenbeck 1995), to cytosine for pairing only with inosine and not with adenosine. Although the resulting HHR certainly showed specific cleavage activity against the edited target RNA, inverse recognition could not be achieved using the same design strategy because there is no natural nucleotideforming base pair with only adenosine and not inosine. In order to generate an HHR with unedited-specific cleavage activity, another HHR strategy is required.

Here, we report a strategy for constructing an artificial exHHR specifically cleaving target RNA when the target editing site is adenosine but not inosine in order to develop a method for target RNA cleavage based on A-to-I RNA editing. First, to validate that intrinsic $\mathrm{NHH}$ cleavage specificity can be used for unedited target-specific cleavage, we designed a minHHR in which the first $\mathrm{H}$ position corresponds to the $\mathrm{E}$ site, which is one of the editing sites on HTR2C pre-mRNA, according to conventional HHR design. Next, we performed in vitro selection with a partially randomized HHR library to select an exHHR containing the artificial TSM to construct a more effective HHR. We also showed the framework of the selected HHR could be applied to other target sequence for unedited-specific cleavage. Furthermore, the resulting HHR was applied to cleave HTR2C mRNA extracted from the mouse brain in an unedited-specific manner. This unedited-specific cleavage can also be utilized to analyze the effect of the editing state at the $\mathrm{E}$ and $\mathrm{C}$ site on editing at other sites.

\section{RESULTS}

\section{Ribozyme design for specific unedited-target RNA cleavage based on minimal hammerhead ribozyme}

Since HHR has NHH specificity in target-sequence cleavage (Fig. 1A), engineered trans-HHR does not show cleavage activity on the substrate RNA when the first $H$ position is $G$ (NHH: first $\mathrm{H}$ position is underlined). Additionally, as this position must form a base pair during HHR cleavage activity, this position has been used to facilitate allele-specific cleavage on target RNAs (Dawson and Marini 2000). The chemical structure of inosine is similar to that of guanosine; this specificity could also be applied for A-to-I RNA editing recognition, i.e., to engineer a ribozyme that specifically cleaves substrate RNA only when its target site remains unedited. To determine whether this position can be available for unedited-specific target RNA cleavage, we designed a transHHR based on the minHHR structure to cleave HTR2C RNA depending on the editing state at the $\mathrm{E}$ site, which is one of the editing sites on the HTR2C pre-mRNA (Fig. 1B). According to conventional HHR design, hybridizing arms that form stem I and stem III were designed so that E site was positioned at the first $\mathrm{H}$ position. In this experiment, unedited substrate RNA was labeled UAA (the E site is underlined) and edited substrate was represented as UIA, per $\mathrm{NHH}$ notation. The catalytic core sequence from HH16 (5'CUGAUGAGGCCGAAAGGCCGAA- ${ }^{\prime}$; the hammerhead consensus sequences are underlined), which has been well characterized with regard to its cleavage kinetics and specificity (Hertel et al. 1994, 1996; Kore et al. 1998) was used. The cleavage activity and A-to-I recognition of the designed HHR (minHR-HTR2C-Eedit) was assessed by in vitro cleavage assays using synthetic HTR2C RNA fragments in which the target triplet was UAA (HTR2C-wt) or UIA (HTR2C-Eino) (Fig. 1C). In this assay, each ${ }^{32} \mathrm{P}$-labeled 37 -nucleotide RNA fragment was annealed in the presence of an excess of minHRHTR2C-Eedit to analyze cleavage activity under single-turnover conditions. After starting the cleavage reaction by adding $20 \mathrm{mM} \mathrm{MgCl}_{2}$, cleavage fragments at each reaction time point were separated by denaturing polyacrylamide gel electrophoresis (PAGE), and then the cleavage fractions were determined from the band intensities. In the reaction with HTR2C-wt, a cleavage band was observed after $20 \mathrm{~min}$ (Fig. $1 C$, upper panel), but almost no cleavage was observed at this time point in HTR2C-Eino (Fig. 1C, lower panel). The cleavage fractions were 0.14 for HTR2C-wt and 0.01 for HTR2C-Eino at $120 \mathrm{~min}$. These results indicated that the first $\mathrm{H}$ position could be used for unedited-specific cleavage, but this cleavage activity against unedited-substrate was significantly lower than the general HHR used for target RNA cleavage. In order to construct an HHR with more efficient unedited-specific cleavage activity, it was necessary to improve cleavage activity against the UAA substrate.

\section{Library design and in vitro selection for an extended hammerhead ribozyme with efficient unedited-specific cleavage}

To improve cleavage activity against the UAA substrate, we targeted the basic frame of exHHR. In contrast to minHHR, in which the peripheral loop I is deleted, most natural HHRs have a tertiary stabilizing motif (TSM) formed by interactions between loops I and II (Khvorova et al. 2003). Because these TSMs increase the cleavage activity of HHRs by stabilizing their active structure, they have been utilized for generating trans-acting HHRs with improved target RNA cleavage (Saksmerprome et al. 2004; Carbonell et al. 2011). Therefore, we predicted that the TSM could be used to improve the basic cleavage activity and thus enhance UAA cleavage activity. In designing an extended trans-acting HHR with an optimal TSM for effective target RNA cleavage, we considered the size and nucleotide sequence of the TSM and its location in the HHR structure. Previous studies have generated artificial TSMs by the SELEX method using an HHR library that was partially randomized at loops I or II (Saksmerprome et al. 2004). Indeed, these artificially optimized combinations of the loop sequences improved HHR cleavage activity, but these optimizations were performed using fixed lengths of stems Ia and II. Because the lengths of stems II and Ia affect the position and geometry of the loops, simultaneous optimization of stem length would make construction of optimal TSM for target RNA more efficient. 
Therefore, we generated another partially randomized HHR library in which both the sequence and the length of stemloop II could be optimized against a fixed length of stem Ia and loop I (Fig. 2A). The catalytic core region including stem-loop II and the nucleotide paired with the E site was varied with 21 randomized nucleotides except for the HHR consensus sequence of $5^{\prime}$-CUGA- $3^{\prime}$. Four randomized nucleotides were introduced into the stem I region as an artificial loop I 6 nt downstream from the $5^{\prime}$-CUGA-3' consensus sequence. When introducing loop I at this position, stem Ia was fixed at $6 \mathrm{bp}$. Stem III was forced to form a 6-bp match with the target RNA to select for active HHRs in the following step. In this design, $14 \mathrm{nt}$ could be used to form the stem-loop
A

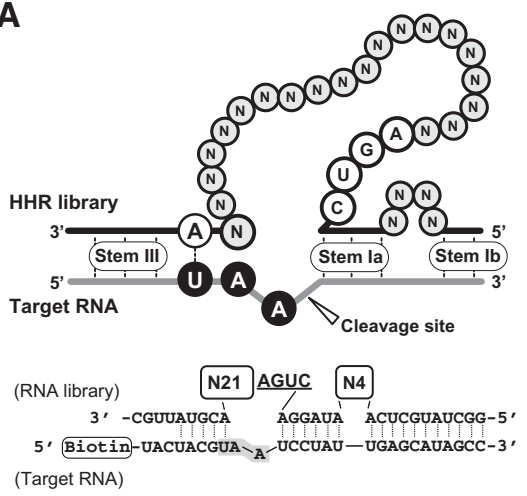

B

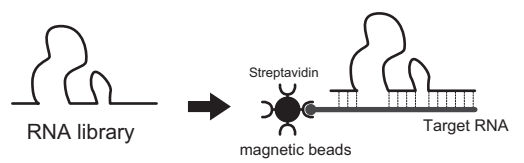

in vitro transcription RT-PCR

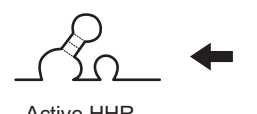

Active HHR structure, where the length of loop II would be 8,6 , or $4 \mathrm{nt}$ when the length of stem II was 3 , 4, or $5 \mathrm{bp}$, respectively. Although the combinations of loop II and stem II lengths were restricted, this HHR library included variable stemloop II structures by fully randomizing the stem-loop II region. We chose to fix the CUGA consensus sequence, because this approach reduced the diversity of the library and restricted the target cleavage site of the selected HHR. Active HHRs cleaving the nascent site were predominantly selected when the catalytic core was fully randomized, because GUA (E site is underlined) is a preferred triplet for HHR cleavage (data not shown). The position of the nucleotide paired with the target-editing site was also randomized, thus permitting the possibility of a new base optimized for the UAA substrate. This RNA library was transcribed in vitro using the double-stranded DNA template generated from partially randomized synthetic oligonucleotides by primer extension. As the target RNA, the synthetic HTR2C RNA fragment was $5^{\prime}$-biotinylated for immobilization on streptavidin magnetic beads (Fig. 2A). The selection was performed according to the reported method for obtaining trans-HHR with slight modifications (Fig. 2B; Persson et al. 2002). First, a gel-purified RNA library was annealed to the $5^{\prime}$-biotinylated target RNA. Next, the RNA library-target RNA complex was immobilized on the magnetic beads through the biotin-avidin interaction. After washing to remove unbound RNA, the cleavage reaction was initiated by adding $20 \mathrm{mM} \mathrm{MgCl}_{2}$. After a 30-min on-bead cleavage reaction, the supernatant containing active HHR was collected. The collected fraction was subjected to reverse-transcription polymerase chain reaction (RT-PCR) to amplify the next DNA library and was transcribed to regenerate the RNA library. After six rounds of selection, each selected RNA was sequenced following the cloning of the DNA library (Fig. 2C). As a result, we obtained three RNA clones (HR-F39, HR-F43, and HR-F48) with the hammerhead consensus sequence (5'-CUGAN GA-GAA- $3^{\prime}$ ) (Fig. 2C, underlined). In each of the HHR candidates, uridine paired with the E site. Based on secondary structural prediction, the lengths of loop II and stem II in HR-F39 and HR-F43 were $6 \mathrm{nt}$ and $4 \mathrm{bp}$, respectively. These lengths were different in HR-F48 as loop II was predicted to be $8 \mathrm{nt}$ and stem II 
A

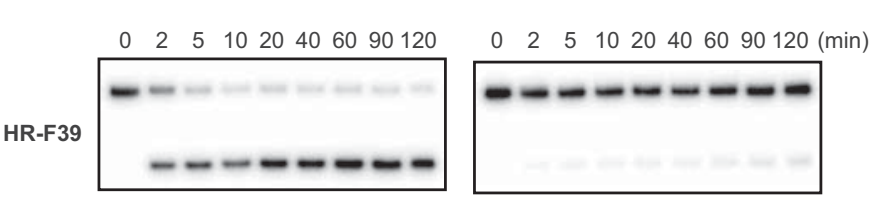

$0 \quad 2 \quad 51020406090120$

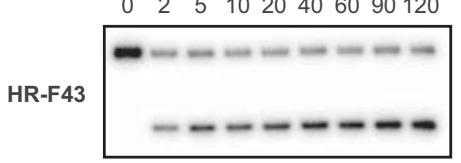

$0 \quad 2 \quad 5 \quad 1020406090120(\min )$

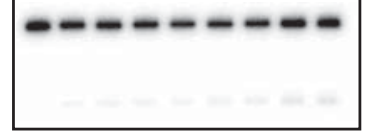

$0 \quad 2 \quad 5 \quad 1020406090120$

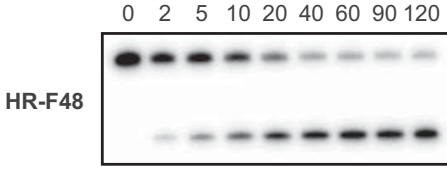

$\begin{array}{llllllll}0 & 2 & 5 & 10 & 20 & 40 & 60 & 90120 \\ (\mathrm{~min})\end{array}$
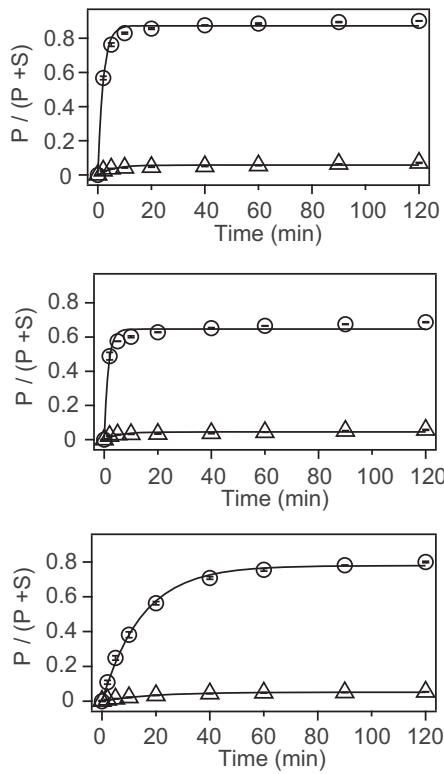

FIGURE 3. Time course of cleavage reaction and kinetic analysis of selected HHRs for the UAA (HTR2C-wt) and UIA (HTR2C-Eino) substrates under single-turnover conditions. (A) Denaturing PAGE (15\%) showing the time course of cleavage of HTR2C-wt (left) and HTR2C-Eino (right) by the selected HHRs. $(B)$ Graphs representing the cleavage ratio as a function of reaction time. Each data point for individual sets of ribozyme and substrate (ribozyme/substrate) is represented as circles (HHR/HTR2C-wt) and triangles (HHR/HTR2C-Eino). The cleavage ratio at different time points was determined using quantitative scanning of the corresponding gel bands and calculated using the expression $\mathrm{P} /(\mathrm{S}+\mathrm{P})$, in which $\mathrm{S}$ and P represent the intensities of the substrate band and cleavage product band, respectively. All data were obtained from two independent experiments for reproducibility. Fitting curves were generated using a single-exponential equation. The kinetic parameters obtained from this experiment are summarized in Table 1.

was predicted to be $3 \mathrm{bp}$. The sequence of stem II was composed of G-C base pairs in all the selected RNAs.

\section{In vitro trans-cleavage activity and specificity of the selected ribozyme against the HTR2C RNA fragment}

In order to verify the cleavage activity and specificity of the selected exHHR candidates, a cleavage assay was performed using $H T R 2 C$-wt and HTR2C-Eino mRNA according to the method described above (Fig. 3). The cleavage rates of HR-F39 and HR-F43 against HTR2C-wt were greater than 100-fold higher than that of miniHR-HTR2C-Eedit (HRF39: $0.49 \mathrm{~min}^{-1}$; HR-F43: $0.65 \mathrm{~min}^{-1}$ ). Although HR-F48 had less activity than the other selected HHRs, the cleavage rates of all the selected HHRs were higher than that of minHHR. The fraction of the product at the endpoint of the reaction $\left(F_{\infty}\right)$ was higher for HTR2C-wt (HR-F39: 0.87; HR-F43: 0.65; HR-F48: 0.78) than for HTR2C-Eino (HRF39: 0.05; HR-F43: 0.04; HR-F48: 0.05) (Table 1). These data indicated that these HHRs efficiently and specifically cleaved HTR2C RNA wherein the E site was unedited.

To assess the validity of introducing the tetra-loop sequence into the partially randomized RNA library, we synthesized HR-F39 (-L) by deleting loop I (GGAA) from HRF39 and subsequently performed the cleavage assay against HTR2C-wt (Supplemental Fig. S1). Based on an analysis of the band intensities, the rate of cleavage and $F_{\infty}$ were $0.006 \mathrm{~min}^{-1}$ and 0.25 , respectively (Table 1 ). These values were lower than those of the parental HR-F39, and the cleavage activity of HR-F39 (-L) was similar to that of minHRHTR2C-Eedit (Supplemental Fig. S1). These data indicated that the artificial tetra-loop sequence significantly improved the cleavage activity.

TABLE 1. Kinetic parameters of hammerhead ribozymes against RNA substrates

\begin{tabular}{llll}
\hline Ribozyme & \multicolumn{1}{c}{ Substrate } & \multicolumn{1}{c}{$k_{\text {cat }}\left(\mathrm{min}^{-1}\right)^{\mathrm{a}}$} & $F_{\infty}^{\mathrm{b}}$ \\
\hline HR-HR2C-Eedit & HTR2C-wt & $0.003 \pm<0.001$ & 0.45 \\
& HTR2C-Eino & $0.001 \pm<0.001$ & 0.05 \\
HR-F39 & HTR2C-wt & $0.49 \pm<0.038$ & 0.87 \\
& HTR2C-Eino & $0.17 \pm 0.058$ & 0.05 \\
& HTR2C-Cino & $0.017 \pm<0.001$ & 0.76 \\
& HTR2C-L-wt & $0.35 \pm 0.015$ & 0.97 \\
& HTR2C-L-Egua & $0.39 \pm 0.44$ & 0.01 \\
HR-F39(-L) & HTR2C-wt & $0.006 \pm<0.001$ & 0.25 \\
HR-F43 & HTR2C-wt & $0.65 \pm 0.095$ & 0.65 \\
& HTR2C-Eino & $0.18 \pm 0.067$ & 0.04 \\
HR-F48 & HTR2C-wt & $0.067 \pm 0.003$ & 0.78 \\
& HTR2C-Eino & $0.054 \pm<0.001$ & 0.05 \\
HR-F39-NEIL1 & NEIL1-ade & $0.05 \pm<0.001$ & 0.81 \\
& NEIL1-ino & $0.02 \pm 0.003$ & 0.00
\end{tabular}

${ }^{\mathrm{a}}$ Cleavage rate constant.

${ }^{b}$ Fraction of product at the end point of the reaction. 
In HTR2C pre-mRNA, there is another editing site, the $\mathrm{C}$ site, adjacent to the $\mathrm{E}$ site, which corresponds to the second $\mathrm{H}$ based on the sequence of HR-F39. Similar to the first $\mathrm{H}$ in the NHH preference, the second $\mathrm{H}$ position cannot be guanosine. If the same strategy could be applied to the second $\mathrm{H}$, this position could also be utilized for HTR2C RNA cleavage in an unedited, C-site-specific manner. In order to assess the cleavage characteristics when the second $\mathrm{H}$ position is inosine, we performed the cleavage assay using HR-F39 against the UAI substrate (HTR2C-Cino) (Fig. 4). The cleavage rate of the HTR2C-Cino $\left(0.017 \mathrm{~min}^{-1}\right)$ was $~ 30$-fold lower than that of the HTR2C-wt RNA fragment. This suggested that C-site editing inhibited the cleavage activity of HR-F39. These results indicated that the second $\mathrm{H}$ position could also be used for unedited-specific cleavage as with the first $\mathrm{H}$ position. In contrast to the cleavage rate for HTR2C-Cino, the $F_{\infty}$ values were sim-

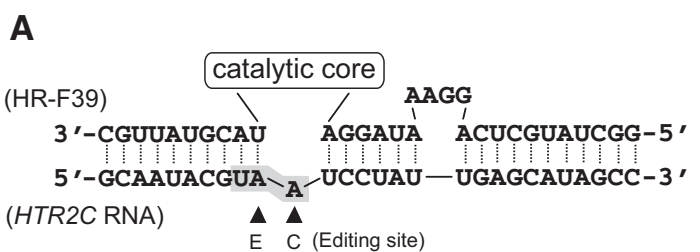

B

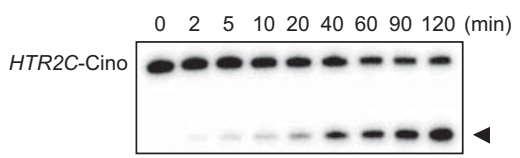

C

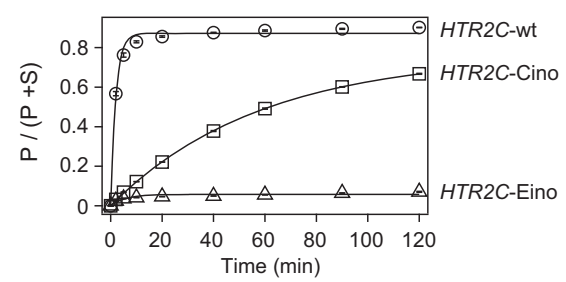

FIGURE 4. Analysis of the cleavage characteristics of HR-F39 for the HTR2C RNA fragment depending on the editing state at the second $\mathrm{H}$ position. (A) Sequence of HR-F39 and part of HTR2C-wt. The nucleotides corresponding to the $\mathrm{NHH}$ triplet are indicated in gray. The $\mathrm{E}$ and $\mathrm{C}$ sites are indicated as black arrowheads. Sequence of the catalytic core including the stem-loop II is $5^{\prime}$-CUGACGAGGCCUCCUACGGCC GAA-3' as shown in Figure 2C. HTR2C-wt edited at the C site is represented as HTR2C-Cino. (B) Cleavage assay for cleavage specificity of HR-F39 at the second H position. Denaturing PAGE (15\%) shows the cleavage activity of HR-F39 for HTR2C-Cino. Positions of the uncleaved substrate and the resulting $5^{\prime}$-cleavage products are indicated. $(C)$ Summary of the cleavage characteristics of HR-F39 for HTR2C RNA fragments that are edited at the first or the second $\mathrm{H}$ position. The graph represents the cleavage ratio of HR-F39/HTR2C RNA as a function of reaction time. The data for HTR2C RNAs are represented as circles (HTR2C-wt), triangles (HTR2C-Eino), and squares (HTR2C-Cino). The data from HTR2C-wt and HTR2C-Eino are the same in Figure 3B. All data were obtained from two independent experiments for reproducibility. Fitting curves were generated using a single-exponential equation. Kinetic parameters obtained from this experiment are summarized in Table 1. ilar for HTR2C-Cino (0.76) and HTR2C-wt (0.87) (Fig. 4C; Table 1). These results indicated that HR-F39 specifically cleaved HTR2C-Cino when the reaction time was short and cleaved HTR2C RNA independent of its C-site editing state when the reaction time was longer. Therefore, in the case of the $\mathrm{C}$ site, HR-F39 can be used for editing-dependent or independent cleavage by controlling the reaction time.

\section{Substrate-sequence and $\mathrm{Mg}^{2+}$-concentration dependency of the selected hammerhead framework}

Several RNAs are subjected to A-to-I RNA editing in various organisms. Since the target sequence of HHR can be changed easily by substituting the sequence at stem I and III, our ribozyme can be applied for unedited-specific cleavage of the other editing site. To determine whether our selected ribozyme framework could be applied to any editing site, we performed a cleavage assay against an mRNA fragment of the human DNA repair enzyme Nei endonuclease VIII-like 1 (NEIL1), which contains a K/R site that is an A-to-I editing site in the coding region (Fig. 5A; Yeo et al. 2010). Accordingly, for unedited-specific cleavage, the HHR was designed to hybridize with NEIL1 RNA in the stem I and III region, and the catalytic core and loop II sequences were used in HR-F39 (HRF39NEIL1) (Fig. 5A). The cleavage activity against unedited NEIL1 RNA (NEIL1-ade) was significantly higher than that of edited NEIL1 RNA (NEIL1-ino) (Fig. 5B,C). Compared with the cleavage rate of unedited HTR2C and NEIL1, the rate of HRF39-NEIL1 activity against NEIL1-ade $\left(k_{\text {cat }}\right.$ : $0.051)$ was slower than that against HTR2C. Although the sequence around the cleavage site changed the cleavage characteristics of the HR-F39 framework, our editing recognition design was effective for unedited-specific cleavage of target RNAs other than HTR2C.

Cleavage activity of HHR is highly restricted by low $\mathrm{Mg}^{2+}$ concentration. Since physiological $\mathrm{Mg}^{2+}$ concentrations are thought to be submillimolar, HHR must be active at physiological $\mathrm{Mg}^{2+}$ concentrations in order to be used for intracellular applications. To test the potential of selected HHR for intracellular applications, we analyzed the cleavage activity of HR-F39 under different $\mathrm{Mg}^{2+}$ concentrations. The cleavage assay was performed using HTR2C-wt and HR-F39 in buffers containing $1,2,5$, and $10 \mathrm{mM} \mathrm{MgCl}_{2}$. The cleavage rate was highest at $20 \mathrm{mM} \mathrm{MgCl}_{2}$ and decreased as the $\mathrm{MgCl}_{2}$ concentration decreased (Fig. 5D). The $F_{\max }$ values were similar in buffers with 5, 10, and $20 \mathrm{mM} \mathrm{MgCl}_{2}$ (Figs. 3B; 5D), but there was a significant reduction between 5 and $2 \mathrm{mM} \mathrm{MgCl}_{2}$. At 1 $\mathrm{mM} \mathrm{MgCl}_{2}$, the cleavage activity was nearly absent. These results indicated that HR-F39 is not suitable for use in vivo. Since the HHRs constructed in this study were selected under conditions of $20 \mathrm{mM} \mathrm{MgCl}_{2}$, it is not surprising that the cleavage activity was reduced at lower $\mathrm{Mg}^{2+}$ concentrations. In a previous study, the limitation of $\mathrm{Mg}^{2+}$ concentration was overcome with the TSM (Saksmerprome et al. 2004). Therefore, our method may be used to optimize HHR for 
A

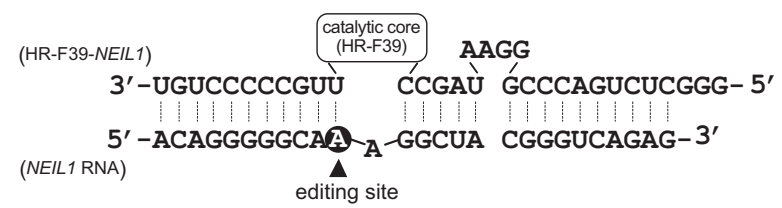

B

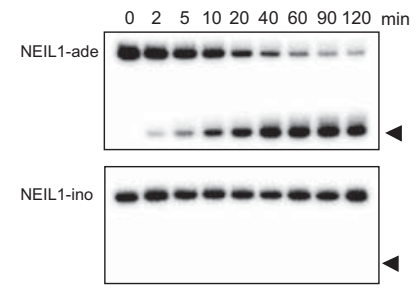

C

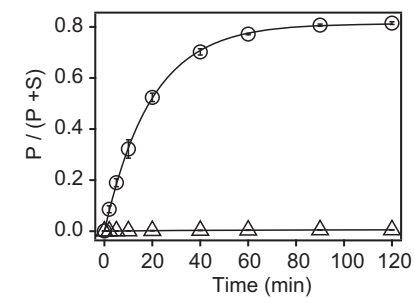

D

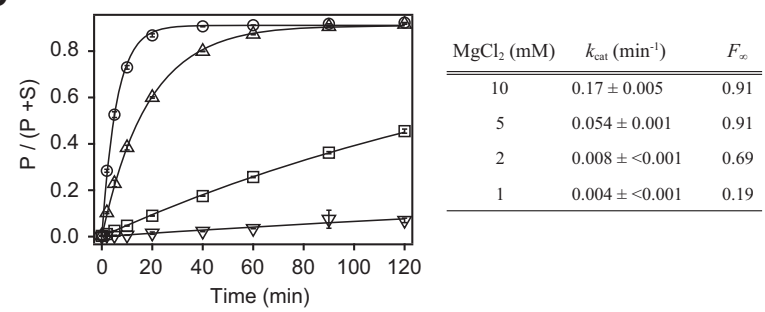

FIGURE 5. Substrate-sequence and $\mathrm{Mg}^{2+}$-dependent cleavage activity of the selected HHR. (A) The nucleotide sequences of the HHR based on the HR-F39 framework targeting the A-to-I editing site on NEIL1 mRNA (HR-F39-NEIL1) and the synthetic NEIL1 RNA fragment (NEIL1 RNA). The sequence of the catalytic core was used for the HR-F39 sequence. The adenosine editing sites on the HTR2C RNA are indicated with black arrowheads. (B) Analysis of A-to-I unedited-specific cleavage by HR-F39-NEIL1 using denaturing PAGE (15\%). The cleavage reaction was performed with NEIL1 RNA in which the editing site was adenosine (NEIL1-ade) or inosine (NEIL1-ino) in the presence of excess HR-F39NEIL1 at $37^{\circ} \mathrm{C}$ for different durations. The positions of the resulting $5^{\prime}-$ cleavage products $(\mathrm{P})$ are indicated. $(C)$ Graphs representing the cleavage ratio as a function of reaction time. Each data point for individual sets of ribozyme and substrate (ribozyme/substrate) is represented as circles (HR-F39-NEIL1/NEIL1-ade) and triangles (HR-F39-NEIL1/NEIL1ino). (D) Cleavage activity of HR-F39 against HTR2C-wt RNA under the low $\mathrm{Mg}^{2+}$ concentrations. Data points at the various $\mathrm{Mg}^{2+}$ concentrations are as follows: (circles) $10 \mathrm{mM}$; (triangles) $5 \mathrm{mM}$; (squares) $2 \mathrm{mM}$; (inverted triangles) $1 \mathrm{mM}$. The cleavage ratios at different time points were determined by quantitation of the corresponding gel bands and calculated by $\mathrm{P} /(\mathrm{S}+\mathrm{P})$, where $\mathrm{S}$ and $\mathrm{P}$ represent the intensity of the substrate band and cleavage product band, respectively. All data were obtained from two independent experiments to ensure reproducibility. Best-fit curves were generated using a single-exponential equation. The kinetic parameters obtained from this experiment are summarized in Table 1.

intercellular applications by changing the $\mathrm{Mg}^{2+}$ requirement to a physiological concentration.

\section{Efficient unedited-specific cleavage against long target RNA and the correlation between the editing ratio determined by the cleavage assay and the direct- sequencing method}

We next evaluate whether our HHR applies not only to short synthetic RNA but also to longer RNA, such as mRNA ex- tracted from cells. As shown in the previous experiment, utilizing ${ }^{32} \mathrm{P}$-labeled target RNA and PAGE is an effective method for analyzing cleavage activity against short RNA. However, this method is not feasible for long target RNA, especially in an extracted RNA. For this kind of target RNA, direct sequencing using fluorescent dideoxy sequencing could be an alternative method for analyzing editing-dependent cleavage. Since inosine is converted to guanosine during RT-PCR, the editing ratio at sites of interest can be analyzed by calculating the A and $\mathrm{G}$ (or $\mathrm{C}$ and $\mathrm{T}$ ) peak heights obtained from the sequencing chromatogram (Nurpeisov et al. 2003; Eggington et al. 2011). Therefore, we analyzed the unedited-specific cleavage activity of our HHR by quantifying the change in the editing ratio from the initial ratio. To validate this analytical method, we performed the following experiment and simultaneously analyzed unedited-specific cleavage by both analytical PAGE and direct sequencing. First, we analyzed unedited-specific cleavage of HR-F39 against long HTR2C RNA by analytical PAGE according to the experiment described for short RNA. As a target RNA in this assay, a 192-nt HTR2C RNA fragment around the 5' editing site was synthesized by in vitro transcription (HTR2C-L-Eade), and the adenosine at the $\mathrm{E}$ site was substituted to guanosine as an analog of inosine (HTR2C-L-Egua). As expected, the results of cleavage assay showed that HR-F39 efficiently cleaved HTR2C-L-Eade, and there was almost no cleavage activity against HTR2C-L-Egua (Fig. 6A). The cleavage activity and specificity for long $H T R 2 C$ RNA were similar to those of short HTR2C RNA (Fig. 3A,B). Next, we analyzed HR-F39 cleavage activity by direct sequencing. To do so, the target RNA was prepared by mixing HTR2C-L-Eade and HTR2C-L-Egua at a molar ratio of 5 to 1 . The cleavage reaction was performed with $2 \mathrm{nM}$ of mixed RNA and $1 \mu \mathrm{M}$ of HR-F39. After initiation of the cleavage reaction by adding $20 \mathrm{mM} \mathrm{MgCl}$, the cleavage samples were subject to RTPCR and direct sequencing to analyze the editing ratios at each time point. The editing ratios increased over time from an initial editing ratio of 0.19 to a final editing ratio of 0.88 (Fig. 6B).

Additionally, we assessed the correlation between the cleavage of unedited HTR2C RNA by HR-F39 and the fraction of unedited HTR2C RNA determined by direct sequencing. Ignoring the cleavage of edited HTR2C RNA, the theoretical editing ratio can be calculated with the following equation, which takes into account the initial editing ratio measured by direct sequencing and the cleavage ratio measured by analytical PAGE: ER $=$ ERini/[(1-URini $) \times C R]$, where ER is the editing ratio; ERini and URini are the initial editing and un-editing ratio, respectively; and CR is the cleavage ratio. A scatter plot demonstrates the correlation between the experimental editing ratio and the calculated editing ratio (Fig. 6C). The trendline for the scatter plot had a $y$-intercept of 0.00 and a slope of 0.92 , and the Pearson $R$ value was 1.00 . These results demonstrate that the unedited-specific cleavage of HR-F39 can be analyzed using direct sequencing. 
A

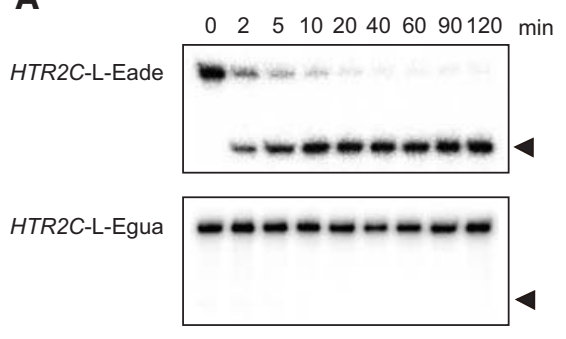

B

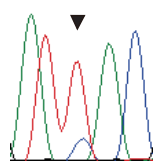

initial

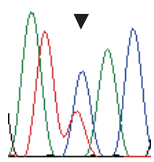

$10 \mathrm{~min}$

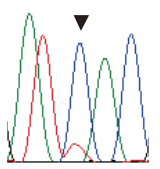

$60 \mathrm{~min}$

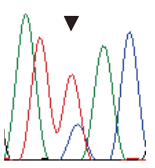

$2 \min$

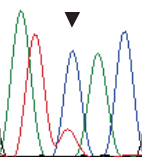

$20 \mathrm{~min}$

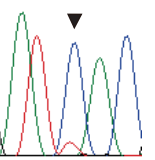

90 min

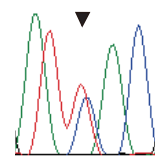

$5 \min$

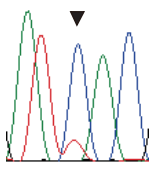

40 min

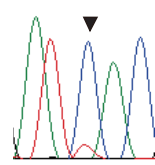

$120 \mathrm{~min}$
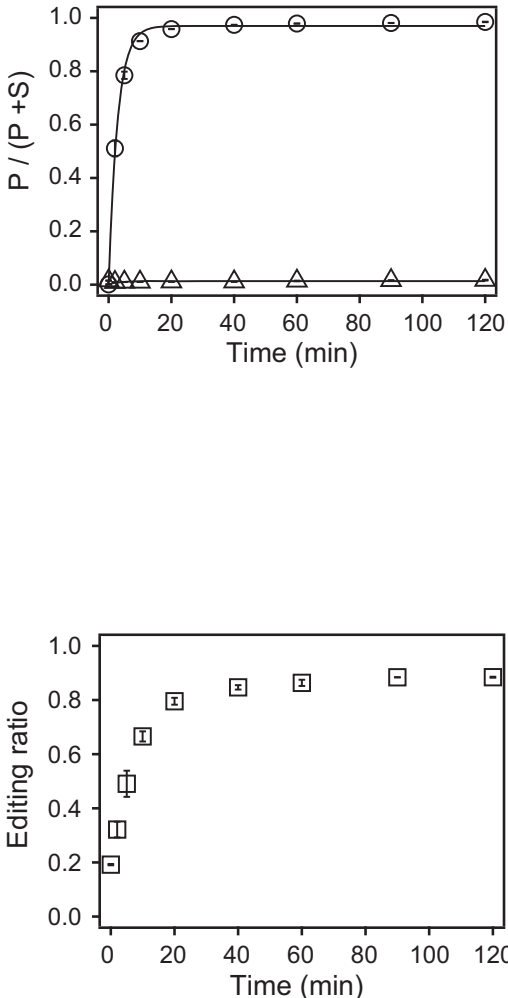

C

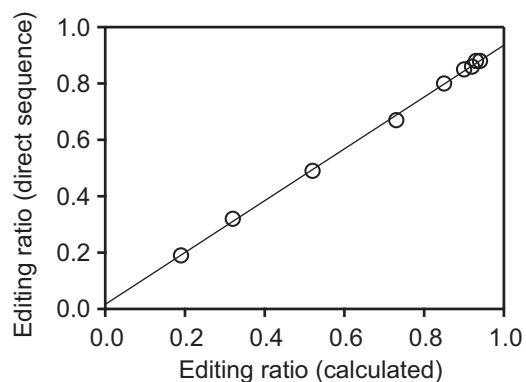

FIGURE 6. Efficiency of unedited-specific cleavage against long target RNA as assessed by analytical PAGE and direct sequencing. (A) Denaturing PAGE (15\%) shows the cleavage activity of HR-F39 for HTR2C-L-wt (upper) and HTR2C-L-Egua (lower), in which adenosine at the E site was substituted to guanosine as an analog for inosine. Positions of the uncleaved substrate and the resulting $5^{\prime}$-cleavage products are indicated. Graphs represent the cleavage ratio as a function of reaction duration. Each data point for individual sets of ribozyme and substrate (ribozyme/substrate) is represented as circles (HR-F39/HTR2C-L-wt) and triangles (HR-F39/ HTR2C-L-Egua). (B) Analysis of unedited-specific cleavage activity by direct sequencing. The sequencing chromatograms generated with the reverse primer are shown at different durations of the cleavage reaction. Red and blue peaks represent $\mathrm{T}$ and $\mathrm{C}$, respectively. The duration of the cleavage reactions is represented under each chromatogram. The E site is indicated with a black arrowhead. The graph shows the editing ratio, calculated as (height of the $\mathrm{C}$ peak)/(height of $\mathrm{C}$ peak + height of $\mathrm{T}$ peak), as a function of the reaction duration. $(C)$ Correlation between editing ratios obtained from direct sequencing and those calculated with the cleavage assay. The calculated editing ratio was estimated as follows: $\mathrm{ER}=\mathrm{ERini} /[(1-$ Urini $) \times \mathrm{CR}]$, where ER is the editing ratio; ERini is the initial editing ratio; URini is the unediting ratio; and CR is the cleavage ratio. The graph plots the correlation, where the $x$-axis is the calculated editing ratio from the cleavage assay, and the $y$-axis is the experimental editing ratio obtained from direct sequencing. The best-fit trendline is shown; the $y$-intercept is 0.00 ; the slope is 0.92 ; and the Pearson $R$ value is 1.00 .

\section{A-to-I RNA editing-dependent cleavage of physiological HTR2C mRNA extracted from mouse brain and the effect of E- and C-site editing state on editing at other sites}

We next assessed the unedited-specific cleavage activity of the ribozyme against HTR2C mRNA extracted from mouse brain. Since there is a basal rate of HTR2C mRNA editing, extracted total RNA was expected to contain a mixture of HTR2C mRNA edited at the $\mathrm{E}$ site and/or C site (Fig. 8A, control, see below). First, we determined the cleavage efficiency of HR-F39 against extracted HTR2C mRNA by reverse-transcription quantitative PCR (Fig. 7A). Total RNA extracted from mouse brain was annealed with and without excess HR-F39 followed by the cleavage reaction. At different time points after initiation of the cleavage reaction $(0,30$, and $60 \mathrm{~min})$, RNA samples were subjected to reverse transcription with random-hexamer primers in order to generate HTR2C cDNA. Then, to quantify the reduction in HTR2C mRNA due to HHR cleavage, qPCR was performed using HTR2C-specific primers that amplify the cDNA around the $\mathrm{E}$ and $\mathrm{C}$ sites (Fig. 7B). In the HHR reaction, HTR2C mRNA was reduced to $\sim 20 \%$ after a 60 -min reaction, and the cleavage reaction was saturated at $30 \mathrm{~min}$. Although we confirmed that HR-F39 cleaved HTR2C mRNA efficiently, it remained unclear whether this reaction was dependent on E- and C-site editing state. Therefore, in order to quantify the efficiency of unedited-specific cleavage, we analyzed the change in editing ratio associated with the cleavage reaction of HRF39 at the E and C sites (Fig. 7A). To quantify the A-to-I editing ratios at the $\mathrm{E}$ and $\mathrm{C}$ sites, RT-PCR fragments were subjected to direct sequencing with the reverse primer. Each editing ratio was calculated by measuring the $\mathrm{T}$ and $\mathrm{C}$ peak heights in the resulting sequencing chromatograms (Fig. 7C). As compared with the change in the editing ratio at the $\mathrm{E}$ site without HR-F39 (Fig. 5C, open circles), the editing ratio with HR-F39 increased over time, with ratios of $0.04,0.12,0.13$, and 0.15 at $0,0.5,1$, and $6 \mathrm{~h}$, respectively 
A
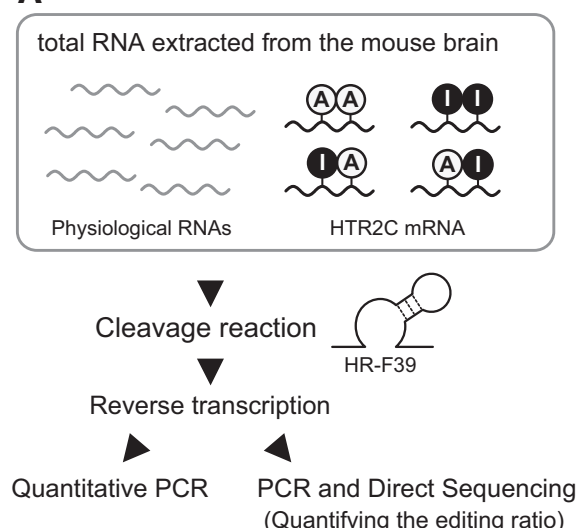

(Quantifying the editing ratio)
B

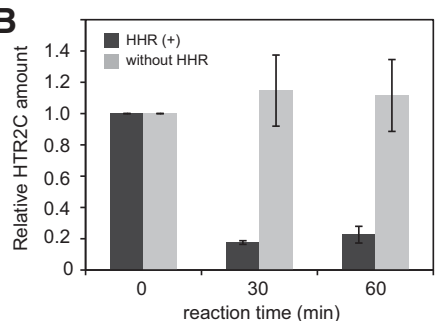

C

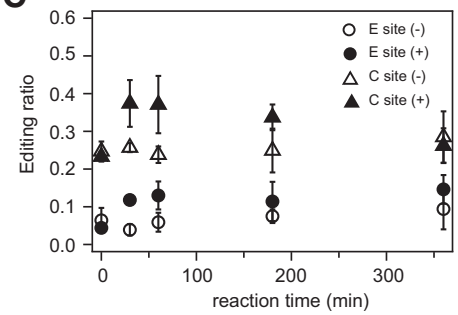

FIGURE 7. In vitro unedited-specific cleavage activity of HR-F39 against HTR2C mRNA extracted from mouse brain. (A) Experimental procedure for analyzing the unedited-specific cleavage activity of HR-F39 against extracted HTR2C mRNA using RT-qPCR and measuring the change in editing ratio at the $\mathrm{E}$ and $\mathrm{C}$ sites. First, total RNA containing HTR2C mRNA was extracted from mouse brain. Among the extracted total RNA, the possible combinations of editing states at the $\mathrm{E}$ and C site (E-C) of HTR2C mRNA are A-A, A-I, I-A, and I-I. Next, to perform unedited-specific cleavage, extracted HTR2C mRNA was reacted with HR-F39 in the total RNA solution. A control sample was generated by omitting HR-F39. Then, the resulting RNAs were subject to reverse transcription to generate HTR2C cDNA. To analyze cleavage efficiency, qPCR was performed with $H T R 2 C$ cDNA generated as described above. The efficiency for unedited-specific cleavage was assessed by measuring the change in the editing ratio calculated from the sequence chromatogram generated by direct sequencing of the RT-PCR product. (B) Reduced HTR2C mRNA after the HR-F39 cleavage reaction. The graph shows relative HTR2C mRNA quantities normalized to that at time zero. The amount of each $H T R 2 C$ mRNA was calculated relative to that of $G A P D H$, which was used as an internal standard for the total RNA quantity. (C) Change in the editing ratio at the $\mathrm{E}$ and $\mathrm{C}$ sites over time with HR-F39. The graph shows the editing ratio at the $\mathrm{E}$ and $\mathrm{C}$ sites as a function of time for the cleavage reaction. Each editing ratio was quantified by measuring the peak heights of $\mathrm{T}$ and $\mathrm{C}$ generated from the direct-sequencing chromatograms and calculated as follows: (height of the $\mathrm{C}$ peak)/(height of $\mathrm{C}$ peak + height of $\mathrm{T}$ peak). Circles and triangles represent the editing ratio at the $\mathrm{E}$ and $\mathrm{C}$ sites, and open and closed symbols indicate without and with HR-F39, respectively. The results of $B$ and $C$ are presented as averages and standard deviations from three independent experiments.

(Fig. 7C, closed circles). Combined with the results of qPCR, this increase in the editing ratio indicated that HR-F39 specifically cleaved HTR2C RNA with an unedited E site. Using the equation shown above, we estimated that $\sim 73 \%$ of uneditedHTR2 $C$ was cleaved in a $1-\mathrm{h}$ reaction. This altered editing ratio was confirmed by qPCR. These results showed that HR-F39 could cleave physiological HTR2C mRNA from tissue-extracted total RNA in an unedited-specific manner.

In the case of the $\mathrm{C}$ site (Fig. 7C, triangles), the change in editing ratios differed with and without the HR-F39 reaction. However, with the HR-F39 reaction, these changes were bidirectional, and the editing ratios were $0.23,0.37,0.37$, 0.34 , and 0.26 at each time point (Fig. $7 \mathrm{C}$, closed triangles). Based on the cleavage characteristics of HR-F39 against HTR2C-Cino shown in the above experiment (Fig. 4), we concluded that the increase in editing ratio at the initial stage of the cleavage reaction resulted from the specific cleavage of the unedited mRNA at the $\mathrm{C}$ site. In contrast, a gradual reduction in the ratio was observed for longer reaction times due to the cleavage of edited HTR2C mRNA. Under physiological conditions, HTR2C mRNA is subject to A-to-I RNA editing not only at the $\mathrm{E}$ site but also at the $\mathrm{C}$ site. Therefore, the possible sequence combinations of the $\mathrm{E}$ and $\mathrm{C}$ sites $(\mathrm{E}-\mathrm{C})$ are A-A, A-I, I-A, and I-I (Fig. 7A). Based on results of the in vitro cleavage assay, we predicted the order of the cleavage events in physiological HTR2C mRNA to be A-A first and then I-A; thereafter, most of the A-I and I-I sequences would remain even after long reaction times. This cleavage order was also observed as a bidirectional change in the editing ratio at the $\mathrm{C}$ site with reaction time (Fig. 7C). These results showed that our HHR cleaved HTR2C mRNA not only at the E site but also at the C site in an editing-dependent manner.

In physiological conditions, HTR2C pre-mRNA is edited not only at the E and $\mathrm{C}$ sites but also at three other sites (A, $\mathrm{B}$, and $\mathrm{D}$ sites) in the proximal region (Fig. 8A). As shown in Figure 8A, the direct-sequencing method has the advantage of being able to simultaneously analyze the editing ratios at multiple sites. Additionally, cDNA generated from unedited HTR2C mRNA at both the $\mathrm{E}$ and $C$ sites were preferentially removed from the total HTR2C mRNA species by the HR-F39 cleavage reaction for $30 \mathrm{~min}$ in which cleavage reaction seems to be saturated. Using the direct-sequencing method combined with HR-F39 cleavage, we were able to analyze the editing ratio at the $\mathrm{A}, \mathrm{B}$, and $\mathrm{D}$ sites on HTR2C mRNA that has been edited at the $\mathrm{E}$ and/or $\mathrm{C}$ sites. Therefore, the effect of the editing state at the $\mathrm{E}$ and/or C site to editing at the other three sites would be assessed as a change in the editing ratio along with the cleavage reaction. For example, if editing at the $\mathrm{E}$ and/or $\mathrm{C}$ sites strongly suppresses editing at another site, the editing ratios at that site will be decreased by HR-F39 cleavage. As a result, although changes in the editing ratios at the $\mathrm{E}$ and $\mathrm{C}$ sites were observed in the sample with a 30-min cleavage reaction, the $\mathrm{A}, \mathrm{B}$, and $\mathrm{D}$ sites showed an almost constant ratio regardless of the reaction (Fig. 8B). These results suggest that editing at the $\mathrm{E}$ and $\mathrm{C}$ sites does not correlate to editing at the other sites.

\section{DISCUSSION}

A-to-I RNA editing regulates several biological processes (Nishikura 2010), such as signal transduction of neurological receptors, including GRIA2 and HTR2C. We previously 


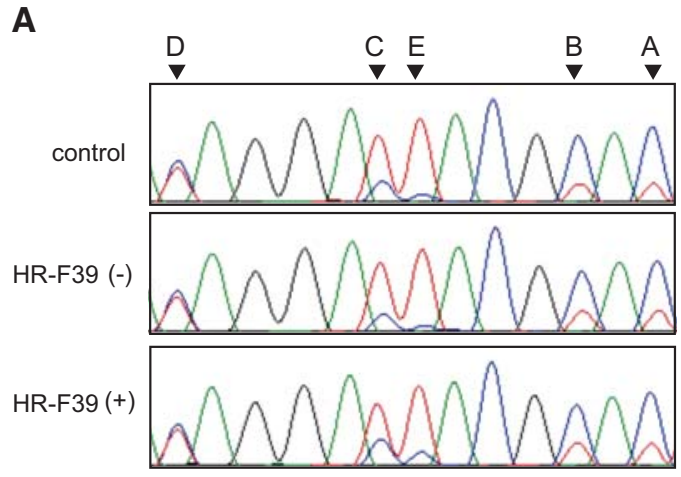

B

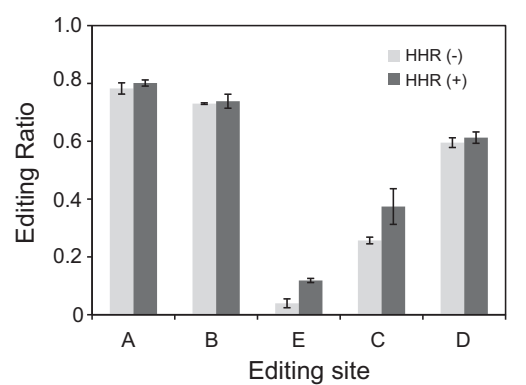

FIGURE 8. Analysis of the effect of editing state at the $\mathrm{E}$ and/or $\mathrm{C}$ sites on editing at the other sites on HTR2C mRNA. (A) Sequence chromatograms of the RT-PCR products with and without the cleavage reaction by HR-F39. Chromatograms, which were generated using reverse $H T R 2 C$-specific primers, are shown for the sequences obtained from intact HTR2C mRNA (upper), incubation only (without cleavage reaction) (middle), and after the reaction with HR-F39 for 30 min (lower). Red and blue peaks represent the signals from $\mathrm{T}$ and $\mathrm{C}$, respectively. Each editing site is indicated using an arrowhead. (B) Comparison of editing ratios at each editing site with and without cleavage reaction. The bar graph shows the editing ratios at each editing site from the HR-F39 reaction (dark gray bars) and without the reaction (light gray bars). Editing ratios were quantified by the same method as in Figure 5C. Results are presented as the average editing ratio and standard deviation from three independent experiments.

developed a strategy for HHR cleavage of target RNA when a specific site is subjected to A-to-I RNA editing (Fukuda et al. 2012). In this report, we next developed an HHR with an inverse sequence specificity, i.e., one that cleaves substrate RNA only at unedited target sites. However, we were unable to construct the desired HHR with the previous method of HHR design in which editing-specific cleavage depended on whether a recognition base on the HHR base-paired to the target-editing site on the substrate, because there is no natural nucleotide that base-pairs with adenosine instead of inosine. Because we were unable to use an editing recognition strategy utilizing base-pair formation, we instead designed HHRs using the intrinsic cleavage specificity of $\mathrm{HHR}$, called $\mathrm{NHH}$ specificity. As expected, minHR-HTR2C-Eedit specifically cleaved an HTR2C RNA fragment with an unedited E site (Fig. 1B), but both the $k_{\text {cat }}$ and the $F_{\infty}$ of minHR-HTR2C-Eedit were low. Since the preferred substrate of wild-type HHR is the NUH triplet (Ruffner et al. 1990; Perriman et al. 1992; Kore et al. 1998), it was reasonable that the designed minHHR had a low level of activity against the UAA substrate. Therefore, we expected that the addition of a TSM would increase the cleavage activity of minHHR against UAA as well as improve its basic cleavage activity. The in vitro selection successfully yielded three exHHRs with significantly higher activity against the UAA substrate than HR-HTR2C-Eedit (Fig. 3). As expected, the selected ribozymes specifically cleaved unedited RNA in a manner similar to HR-HTR2C-Eedit. Indeed, deletion of loop I significantly decreased the cleavage activity of HR-F39 to levels as low as that of minHHR-HTR2C-edit (Supplemental Fig. S1). Therefore, we concluded that loop I improves the cleavage activity due to the formation of the TSM with loop II.

Sequencing analysis of selected HHRs revealed that the length of stem II was 4 bp in F39 and F43 but 3 bp in F48. The catalytic rate of F48 was lower than F39 and F43, indicating that cleavage activity is affected not only by the combination of the loop sequence but also by the length of stem II. In our HHR library design, in which the length of stem Ia was fixed at $6 \mathrm{bp}$, the length of stem II suitable for forming a stable TSM might be $4 \mathrm{bp}$. At the nucleotide position paired with the editing site, $U$ was selected in all RNAs, indicating that $\mathrm{U}$ optimally forms a Watson-Crick base pair at this position even if the substrate RNA sequence is UAA. Unfortunately, the number of selected RNAs in this experiment was too small to make a generalization about the optimal sequence combination between loops I and II.

In addition to the first $\mathrm{H}$ of $\mathrm{NHH}$, the second $\mathrm{H}$ position has also been utilized for mutation-specific cleavage (Parthasarathy et al. 1999). Although A-to-I editing recognition was lower when HHRs were designed using the second $\mathrm{H}$ position, they had the advantage of allowing either editingdependent or independent cleavage by adjusting the reaction time.

We demonstrated that our strategy of HHR framework selection could be applied not only to HTR2C but also to other RNAs, such as NEIL1 RNA, for unedited-specific cleavage. However, the cleavage rate against unedited RNA was affected by the sequence surrounding the editing site. This indicated that the TSM of HR-F39 had some target-sequence dependency. This sequence dependency might have resulted from optimizing the HR-F39 framework to the HTR2C sequence. Cleavage activity was also $\mathrm{Mg}^{2+}$-concentration dependent, as cleavage activity of HR-F39 was inhibited by low $\mathrm{Mg}^{2+}$ concentration. These results indicated that the HR-F39 framework was not suitable for intercellular application without any further modification. However, it has been reported that TSM effectively overcame $\mathrm{Mg}^{2+}$ restriction of HHR. Therefore, our method might be used to construct an optimal HHR with both an editing-recognition property and activity at low $\mathrm{Mg}^{2+}$ concentrations by changing the selection conditions appropriately.

We demonstrated that editing-specific cleavage of the HHR is applicable to not only short HTR2C RNA fragments 
but also mRNA extracted from mouse brain. First, we established an analytical method for quantifying unedited-specific cleavage using direct sequencing. The editing ratios calculated from the analytical PAGE were highly correlated with those calculated from direct sequencing (Pearson $R$ value $=$ 1.00). We assessed the efficiency of unedited-specific cleavage by qPCR and by quantifying the change in the editing ratio at $\mathrm{E}$ and $\mathrm{C}$ sites (Fig. 5A). Our results indicated that the saturation value and cleavage rate were similar to those obtained in the reaction against the HTR2C RNA fragment. In the case of minHHR, the in vitro trans-cleavage constant against the long substrate was $>100$-fold lower than that against the short substrate (Campbell et al. 1997; Hormes and Sczakiel 2002; Fukuda et al. 2012). The reason for this decrease in cleavage activity may be an inability to form the proper active conformation through base-paired, nonspecific interactions with ribozyme nucleotides. In exHHR, it is thought that the TSM would mitigate the negative effects of a long substrate through stabilizing the active structure with an intermolecular interaction.

Since the five editing sites on HTR2C are close together, it has been proposed that editing at one site would correlate with further editing at other sites (Du et al. 2006; Enstero et al. 2009; Carmel et al. 2012). This has been supported by sequence analysis of the editing pattern of each HTR2C mRNA clone using canonical cloning methods or highthroughput sequencing methods. Alternatively, HHR's editing-dependent target-cleavage activity could be utilized as a method for analyzing such interdependencies among editing states. The HR-F39 cleavage reaction specifically reduces molecular species in which both the $\mathrm{E}$ and $\mathrm{C}$ sites are unedited in the total HTR2C mRNA. In our study, editing ratios at the A, $B$, and $D$ sites were not altered, regardless of the reaction with HR-F39. This suggests that editing at the A, B, and D sites are independent or weakly correlated with the editing state at the $\mathrm{C}$ and $\mathrm{E}$ sites. Alternatively, this could suggest that the order of editing events occurs as follows: The A, B, and D sites are edited more rapidly than the $\mathrm{C}$ and $\mathrm{E}$ sites.

The C site in HTR2C pre-mRNA is thought to be subject to 2'-O-methylation by a small nucleolar RNA (snoRNA), MBII-52, which guides methyltransferase to the $C$ site using a HTR2C-complementary sequence (Nahkuri et al. 2008; Kishore et al. 2010). Since the $\mathrm{C}$ site corresponds to the cleavage site in our HHR design (Fig. 2A), HR-F39 cannot cleave HTR2C RNA when the $\mathrm{C}$ site is $2^{\prime}$-O-methylated. Hence, in addition to the HTR2C mRNA edited at the E site, $2^{\prime}$-O-methylated HTR2C mRNA, if present, would be located in the uncleaved fraction after the cleavage reaction. Accordingly, another potential use of HR-F39 may be in evaluating the relationship between $2^{\prime}$-O-methylation and each editing state based on the editing pattern of HTR2C mRNA in the uncleaved fraction. These analyses are currently underway.

In conclusion, we have developed a method for designing HHR with unedited-specific target RNA cleavage. In order to improve the efficiency of unedited target cleavage, exHHRs with a TSM were generated from the partially randomized HHR library by in vitro selection. The resulting exHHRs had higher cleavage activities than minHHR without compromising editing recognition. Our ribozyme can be used for the selective cleavage of not only synthetic RNA fragments but also HTR2C mRNA extracted from mouse brain. Additionally, we reported a useful method using uneditedspecific cleavage and direct-sequencing methods for analyzing the dependencies among the editing states at each editing site without requiring a large amount of sequencing analysis.

\section{MATERIALS AND METHODS}

\section{General}

Reagents and solvents were purchased from standard suppliers and used without further purification. DNA oligonucleotides were purchased from Genenet Co., Ltd. Substrate RNAs with inosine and biotin modifications were purchased from Hokkaido System Science Co., Ltd. The sequences of all purchased DNA oligonucleotides and synthetic RNAs are listed in Supplemental Table S1.

\section{Preparation of ribozymes and substrate RNAs}

All ribozymes were synthesized using an in vitro transcription method (AmpliScribe T7 Kit, Epicentre Biotechnologies) using the specific double-stranded DNA template generated from synthetic oligonucleotides (Supplemental Table S1). Generally, for generating the DNA template, $1 \mu \mathrm{M}$ forward DNA oligonucleotide containing the T7 promoter sequence and $1 \mu \mathrm{M}$ reverse DNA oligonucleotide were mixed in the annealing buffer $(50 \mathrm{mM}$ Tris- $\mathrm{HCl}[\mathrm{pH} 7.6]$ and $50 \mathrm{mM} \mathrm{NaCl}$ ). The annealing reaction was performed by denaturing the mixture for $3 \mathrm{~min}$ at $95^{\circ} \mathrm{C}$ followed by cooling to room temperature for $15 \mathrm{~min}$, and then the annealing product was elongated using Klenow polymerase (New England Biolabs). In the case of ribozymes selected by in vitro selection, DNA templates were generated from the cloned plasmid DNA containing individual ribozyme sequences by PCR with primers containing the T7 promoter sequence (HRpLib-F primer). The in vitro transcription reaction was performed using template DNA according to the manufacturer's protocol followed by purification using $8 \mathrm{M}$ Urea containing $8 \%$ polyacrylamide gel. The transcribed ribozyme was obtained from the corresponding band using the crush-and-soak method in TE buffer (10 mM Tris- $\mathrm{HCl}[\mathrm{pH} 7.5]$ and $1 \mathrm{mM}$ ethylenediaminetetraacetic acid [EDTA]). After phenol/chloroform extraction and ethanol precipitation, purified ribozymes were dissolved in TE buffer and quantified by measuring absorbance at $260 \mathrm{~nm}$ with each molecular coefficient calculated using OligoAnalyzer 3.1 (Integrated DNA Technologies, Inc.). The substrate RNA for HTR2C-wt was synthesized using the oligonucleotide T7pro-F and HTR2C-wt-R according to the same procedure used for ribozyme preparation. HR-NEIL1 was transcribed using a dsDNA template generated by annealing with the oligonucleotides HR-NEIL1-temp and T7pro-F and purified as described for HR-F39. HTR2C-L-wt DNA for in vitro transcription was generated by PCR using the primers HTR2CL-T7F and HTR2C-L-R and the template plasmid pTK-HTR2C, which was constructed by inserting a 288-bp mouse genomic fragment that includes the $3^{\prime} 178 \mathrm{bp}$ of exon 5 and the $5^{\prime} 110 \mathrm{bp}$ of 
intron 5 of HTR2C. For HTR2C-L-Egua DNA, the template plasmid was pTK-HTR2C-Egua in which adenosine at the E site of pTKHTR2C was substituted by a site-directed mutagenesis method. After the transcription reaction, the resultant 198-nt HTR2C-L-wt RNA and HTR2C-L-Egua RNA were purified using 5\% polyacrylamide gel containing $8 \mathrm{M}$ urea. Other substrate RNAs with sitespecific modifications were purchased from Hokkaido System Science Co., Ltd.; these sequences are summarized in Supplemental Table S1.

\section{Cleavage assay and kinetic analysis}

Cleavage assays were performed using $5^{\prime}$-end-labeled substrate RNAs under single-turnover conditions. Substrate RNAs were $5^{\prime}$ end-labeled with $\left[\gamma^{-32} \mathrm{P}\right]$ ATP (GE Healthcare) using T4 polynucleotide kinase (New England Biolabs). After the labeling reaction, radioactive substrate RNAs were purified using denaturing PAGE according to the crush-and-soak method. In order to analyze the cleavage kinetics of ribozyme under single-turnover conditions, excess amounts of ribozyme $(1 \mu \mathrm{M})$ and substrate $(<0.1 \mu \mathrm{M})$ were first mixed in cleavage buffer (20 mM Tris- $\mathrm{HCl}$ [pH 7.6], $100 \mathrm{mM} \mathrm{NaCl}$, and $20 \mathrm{mM} \mathrm{MgCl}_{2}$ ) without $\mathrm{MgCl}_{2}$, and then the annealing reaction was performed by heating for $3 \mathrm{~min}$ at $80^{\circ} \mathrm{C}$ and slowly cooling to $25^{\circ} \mathrm{C}$ at a rate of $1^{\circ} \mathrm{C} / 10 \mathrm{sec}$, followed by incubation for $5 \mathrm{~min}$ at this temperature. After taking a zero-time fraction, the cleavage reaction was started by the addition of $20 \mathrm{mM} \mathrm{MgCl}_{2}$ at $37^{\circ} \mathrm{C}$. To analyze the $\mathrm{Mg}^{2+}$ dependency of $\mathrm{HR}-\mathrm{F} 39, \mathrm{MgCl}_{2}$ concentrations were adjusted to $10,5,2$, and $1 \mathrm{mM}$. Aliquots were sampled at different time points, and the reaction was quenched by adding the same volume of stop solution (10 mM EDTA and $80 \%$ formamide) on ice. The uncleaved substrate and cleavage products were separated by PAGE on $15 \%$ denaturing gels, and the radioactive intensity of each band was quantified using a Bio-Imaging Analyzer FLA-7000 (Fujifilm). For HTR2C-L-wt and HTR2C-L-Egua, 5\% denaturing gels were used. Each cleavage assay was carried out at least twice to ensure reproducibility. The fraction of cleavage product, $F_{\mathrm{t}}$, at different time points was determined using the corresponding scan data. Pseudo-first-order cleavage rate constants, $k_{\text {cat }}$, were calculated using a nonlinear regression analysis with Igor Pro software (WaveMetrics, Inc.). Data were fit to the single-exponential equation, $F_{\mathrm{t}}=F_{0}+F_{1}\left(1-\mathrm{e}^{-k \mathrm{t}}\right)$, where $F_{0}$ and $F_{1}$ are the product fractions at time zero and at the reaction end point, respectively, and $k$ is the first-order cleavage rate constant $\left(k_{\text {cat }}\right)$.

\section{Preparation of the partially randomized HHR library and in vitro selection}

The partially randomized HHR library was synthesized and purified using the same method as for preparation of ribozymes and substrate RNAs. First, the template DNA for in vitro transcription was generated using HRpLib-F and HRpLib-R including randomized nucleotides by annealing and elongation reactions. The RNA library was transcribed using $1 \mathrm{nmol}$ of the resulting dsDNA template in a $400-\mu \mathrm{L}$ reaction volume according to the manufacturer's protocol. After $3 \mathrm{~h}$ of transcription, the RNA library was purified by denaturing PAGE and quantified using the calculated molecular coefficient in which the average coefficient was used for the randomized region. In vitro selection was performed according to a previously reported method for obtaining trans-HHR with slight modifications (Persson et al. 2002). In the first round, $10 \mu \mathrm{M} 5^{\prime}$-biotinylated substrate RNA (bio-HTR2C RNA) and $15 \mu \mathrm{M}$ RNA library were mixed with $100 \mu \mathrm{L}$ cleavage buffer (20 mM Tris- $\mathrm{HCl}$ [pH 7.6], $100 \mathrm{mM} \mathrm{NaCl}$, and $20 \mathrm{mM} \mathrm{MgCl}$ ) without $\mathrm{MgCl}_{2}$, annealed by heating for $3 \mathrm{~min}$ at $80^{\circ} \mathrm{C}$, and slowly cooled to $25^{\circ} \mathrm{C}$ at a rate of $1^{\circ} \mathrm{C} / 10 \mathrm{sec}$. After the second round of selection, the concentration of the RNA library and bio-HTR2C RNA in the annealing reaction were reduced to one-tenth $(1 \mu \mathrm{M}$ bio-HTR2C RNA and $1.5 \mu \mathrm{M}$ RNA library). The reaction solution was added to $1.2 \mathrm{mg}$ of Dynabeads M-280 Streptavidin (Life Technologies Corporation) in order to immobilize the complex of bio-HTR2C RNA and RNA library onto the beads. After a 15-min incubation for binding, the beads were washed three times with $400 \mu \mathrm{L}$ washing buffer to remove free ribozyme. Afterward, the on-bead cleavage reaction was initiated by adding $400 \mu \mathrm{L}$ cleavage buffer, and the cleavage reaction was performed by incubation for $30 \mathrm{~min}$ at $37^{\circ} \mathrm{C}$. After the cleavage reaction, the supernatant containing ribozyme candidates was collected and purified by ethanol precipitation. All collected ribozymes were subjected to reverse transcription using the HRpLib-RT primer to generate cDNA of the selected ribozymes. After optimizing the PCR for specific amplification, cDNA was amplified by PCR using the HRpLib-F and HRpLib-RT primers. The PCR product, which was purified by phenol/chloroform extraction, ethanol precipitation, and gel-filtration, was used for the next round as the dsDNA template. After five rounds of selection, the recognition sequences of the restriction enzymes EcoRI and BamHI were added at both ends by PCR with HRseq-F-EcoRI and HRseq-R-BamHI and were then cloned into the pUC19 vector for sequence analysis of each selected ribozyme. Twenty-four extracted plasmids from each colony were subject to the sequencing reaction using the M13 universal primer (TaKaRa) and the BigDye Terminator v3.1 Cycle Sequencing Kit (Applied Biosystems). Sequence analysis was performed using a 3130 Genetic Analyzer (Applied Biosystems).

\section{Quantification of editing ratio by the direct-sequencing method}

Sample RNA containing a mix of edited and unedited RNA was prepared by mixing HTR2C-L-Eade and HTR2C-L-Egua at a molar ratio of 5 to 1 . HR-F39 $(1 \mu \mathrm{M})$ and sample RNA $(2 \mathrm{nM})$ were first mixed with annealing buffer $(20 \mathrm{mM}$ Tris- $\mathrm{HCl}[\mathrm{pH}$ 7.6] and $100 \mathrm{mM} \mathrm{NaCl}$ ), and then the annealing reaction was performed as described for the cleavage assay. After the cleavage reaction was initiated by the addition of $20 \mathrm{mM} \mathrm{MgCl}_{2}, 10 \mu \mathrm{L}$ of the reaction solutions were sampled at different time points, and the reaction was quenched by ethanol precipitation. To generate HTR2C-L cDNA, the precipitated RNA was subjected to reverse transcription using the HTR2C-L-R primer with the Transcriptor High Fidelity cDNA Synthesis Kit (Roche) according to the manufacturer's protocol. Using HTR2C-L-T7F and HTR2C-L-R primers, each cDNA was amplified by PCR. Approximately $10 \mathrm{ng}$ PCR product was reacted with the HTR2C-L-R reverse primer and the BigDye Terminator Cycle Sequencing Kit (Applied Biosystems) according to the manufacturer's protocol and then analyzed using a 3130 Genetic Analyzer (Applied Biosystems) to generate sequence chromatograms around the $\mathrm{E}$ site. The heights of the $\mathrm{T}$ and $\mathrm{C}$ peaks at the editing site were measured using Sequence Scanner ver. 1.0 software (Applied Biosystems). Each editing ratio was calculated as follows: (peak height of $\mathrm{C}) /($ peak height of $\mathrm{C}+$ peak height of $\mathrm{A})$. 


\section{Preparation of HTR2C mRNA extracted from the mouse brain}

A 4-wk-old male mouse of C57BL/6J strain was decapitated and its whole brain was removed. This brain specimen was thoroughly homogenized with $5.0 \mathrm{~mL}$ of Sepasol RNA I super reagent (Nacalai Tesque) using a polytron-type homogenizer. The RNA fraction in the lysate was extracted by the addition of a 0.2 volume of chloroform and precipitated by the addition of an equal volume of 2-propanol. RNA was collected by centrifugation, followed by rinsing with $70 \%$ ethanol, and air-dried. The resulting pellet of RNA was suspended in $500 \mu \mathrm{L}$ diethyl pyrocarbonate (DEPC)-treated water and its concentration was estimated by UV absorbance.

\section{Analysis of unedited-specific cleavage of extracted HTR2C MRNA}

The cleavage efficiency of the ribozyme for HTR2C mRNA extracted from the mouse brain was analyzed by qPCR and by quantifying the change in the editing ratio according to the following method. Three hundred nanograms of extracted total RNA was annealed in the presence of excess HR-F39 (final concentration, $10 \mu \mathrm{M}$ ) in an annealing buffer ( $50 \mathrm{mM}$ Tris- $\mathrm{HCl}$ [pH 7.6], $150 \mathrm{mM} \mathrm{NaCl}$ ) by heating for $3 \mathrm{~min}$ at $80^{\circ} \mathrm{C}$ and then cooling on ice. The control samples were generated by the same annealing reaction without ribozyme. The cleavage reaction was initiated by the addition of $20 \mathrm{mM}$ $\mathrm{MgCl}_{2}$ to the annealing sample with RNase inhibitor (NEB), and then incubated for $0.5,1,3$, and $6 \mathrm{~h}$ at $37^{\circ} \mathrm{C}$. After the cleavage reaction, each reaction sample was purified by ethanol precipitation. To generate HTR2C cDNA, all the purified RNA was subjected to reverse transcription using the random hexamer primer (dN6 primer) with the Transcriptor High Fidelity cDNA Synthesis Kit (Roche) according to the manufacturer's protocol. In order to quantify the cleavage efficiency, qPCR was performed using the HTR2C-QS1 and HTR2C-QA4 primers for specific amplification of exon inclusion with Power SYBR(R) Green PCR Master Mix (Applied Biosystems). Simultaneously, glyceraldehyde 3-phosphate dehydrogenase (GAPDH) was also quantified using the GAPDH-QF and $G A P D H-Q R$ primers as an internal standard for quantifying the amount of total RNA. qPCR reaction solutions were comprised of $10 \mu \mathrm{L}$ Power SYBR Green PCR Master Mix, $100 \mathrm{nM}$ sense and antisense primers, and $5 \mu \mathrm{L}$ cDNA sample containing the target template in a final volume of $20 \mu \mathrm{L}$. qPCR reactions were performed under the following conditions: preheating for denaturation for 10 min at $95^{\circ} \mathrm{C}$, and 55 cycles of amplification with $15 \mathrm{sec}$ at $95^{\circ} \mathrm{C}$ and $1 \mathrm{~min}$ at $60^{\circ} \mathrm{C}$ by the LightCycler Nano system (Roche). The relative quantitation method was used to compare differences between samples generated at each cleavage reaction time. Using the analysis software (LightCycler Nano software; Roche), the crossing threshold (Ct) values were analyzed from the fluorescent amplification plot by the second derivative maximum method. The difference in crossing thresholds $(\Delta \mathrm{Ct})$ was calculated for each sample by $\Delta \mathrm{Ct}=\mathrm{Ct}$ $(H T R 2 C)-\mathrm{Ct}(G A P D H)$. The magnitude of the differences between each reaction time point was calculated as follows: $\Delta \Delta \mathrm{Ct}=$ $\Delta \mathrm{Ct}$ [HTR2C initial (without ribozyme) $-\Delta \mathrm{Ct}$ (HTR2C with cleavage reaction)]; the relative amount of $H T R 2 C$ mRNA was estimated by $\mathrm{R}=2^{-\Delta \Delta \mathrm{Ct}}$.

The efficiency of unedited-specific cleavage was analyzed as a change in the editing ratio at the corresponding site due to ribozyme cleavage. The editing ratio of each editing site was quantified using a direct-sequencing method (Nurpeisov et al. 2003; Eggington et al. 2011). After the above reverse transcription reaction, DNA fragments for sequencing were amplified by PCR using HTR2C-e4S and HTR2C-ex65A2 primer and then gel-purified. To generate sequence chromatograms around the editing sites, sequencing was performed using purified PCR product and HTR2C-seq65A reverse primer as described above.

\section{SUPPLEMENTAL MATERIAL}

Supplemental material is available for this article.

\section{ACKNOWLEDGMENTS}

This work was supported in part by a Grant-in-Aid for Young Scientists (B) from the Japan Society for the Promotion of Science (No. 23710263) and funds from the Central Research Institute of Fukuoka University (No. 117106).

Received July 9, 2013; accepted December 10, 2013.

\section{REFERENCES}

Bass BL. 2002. RNA editing by adenosine deaminases that act on RNA. Annu Rev Biochem 71: 817-846.

Bratt E, Ohman M. 2003. Coordination of editing and splicing of glutamate receptor pre-mRNA. RNA 9: 309-318.

Burns CM, Chu H, Rueter SM, Hutchinson LK, Canton H, SandersBush E, Emeson RB. 1997. Regulation of serotonin-2C receptor G-protein coupling by RNA editing. Nature 387: 303-308.

Campbell TB, McDonald CK, Hagen M. 1997. The effect of structure in a long target RNA on ribozyme cleavage efficiency. Nucleic Acids Res 25: 4985-4993.

Carbonell A, Flores R, Gago S. 2011. Trans-cleaving hammerhead ribozymes with tertiary stabilizing motifs: In vitro and in vivo activity against a structured viroid RNA. Nucleic Acids Res 39: 24322444.

Carmel L, Koonin EV, Dracheva S. 2012. Dependencies among editing sites in serotonin 2C receptor mRNA. PLoS Comput Biol 8: e1002663.

Chen LL, DeCerbo JN, Carmichael GG. 2008. Alu element-mediated gene silencing. EMBO J 27: 1694-1705.

Citti L, Rainaldi G. 2005. Synthetic hammerhead ribozymes as therapeutic tools to control disease genes. Curr Gene Ther 5: 11-24.

Dawson PA, Marini JC. 2000. Hammerhead ribozymes selectively suppress mutant type I collagen mRNA in osteogenesis imperfecta fibroblasts. Nucleic Acids Res 28: 4013-4020.

De la Peña M, Gago S, Flores R. 2003. Peripheral regions of natural hammerhead ribozymes greatly increase their self-cleavage activity. EMBO J 22: 5561-5570.

Du Y, Davisson MT, Kafadar K, Gardiner K. 2006. A-to-I pre-mRNA editing of the serotonin $2 \mathrm{C}$ receptor: Comparisons among inbred mouse strains. Gene 382: 39-46.

Eggington JM, Greene T, Bass BL. 2011. Predicting sites of ADAR editing in double-stranded RNA. Nat Commun 2: 319.

Enstero M, Daniel C, Wahlstedt H, Major F, Ohman M. 2009. Recognition and coupling of A-to-I edited sites are determined by the tertiary structure of the RNA. Nucleic Acids Res 37: 69166926.

Farajollahi S, Maas S. 2010. Molecular diversity through RNA editing: A balancing act. Trends Genet 26: 221-230. 
Ferbeyre G, Smith JM, Cedergren R. 1998. Schistosome satellite DNA encodes active hammerhead ribozymes. Mol Cell Biol 18: 3880-3888.

Fukuda M, Kurihara K, Tanaka Y, Deshimaru M. 2012. A strategy for developing a hammerhead ribozyme for selective RNA cleavage depending on substitutional RNA editing. RNA 18: 1735-1744.

Gelinas JF, Clerzius G, Shaw E, Gatignol A. 2011. Enhancement of replication of RNA viruses by ADAR1 via RNA editing and inhibition of RNA-activated protein kinase. J Virol 85: 8460-8466.

Goodchild J. 2002. Hammerhead ribozymes for target validation. Expert Opin Ther Targets 6: 235-247.

Haseloff J, Gerlach WL. 1988. Simple RNA enzymes with new and highly specific endoribonuclease activities. Nature 334: 585-591.

Hertel KJ, Herschlag D, Uhlenbeck OC. 1994. A kinetic and thermodynamic framework for the hammerhead ribozyme reaction. Biochemistry 33: 3374-3385.

Hertel KJ, Herschlag D, Uhlenbeck OC. 1996. Specificity of hammerhead ribozyme cleavage. EMBO J 15: 3751-3757.

Higuchi M, Single FN, Köhler M, Sommer B, Sprengel R, Seeburg PH. 1993. RNA editing of AMPA receptor subunit GluR-B: A basepaired intron-exon structure determines position and efficiency. Cell 75: 1361-1370.

Higuchi M, Maas S, Single FN, Hartner J, Rozov A, Burnashev N, Feldmeyer D, Sprengel R, Seeburg PH. 2000. Point mutation in an AMPA receptor gene rescues lethality in mice deficient in the RNA-editing enzyme ADAR2. Nature 406: 78-81.

Hood JL, Emeson RB. 2012. Editing of neurotransmitter receptor and ion channel RNAs in the nervous system. Curr Top Microbiol Immunol 353: 61-90.

Hormes R, Sczakiel G. 2002. The size of hammerhead ribozymes is related to cleavage kinetics: The role of substrate length. Biochimie 84: 897-903.

Kawahara Y, Zinshteyn B, Sethupathy P, Iizasa H, Hatzigeorgiou AG, Nishikura K. 2007. Redirection of silencing targets by adenosineto-inosine editing of miRNAs. Science 315: 1137-1140.

Khvorova A, Lescoute A, Westhof E, Jayasena SD. 2003. Sequence elements outside the hammerhead ribozyme catalytic core enable intracellular activity. Nat Struct Biol 10: 708-712.

Kishore S, Khanna A, Zhang Z, Hui J, Balwierz PJ, Stefan M, Beach C, Nicholls RD, Zavolan M, Stamm S. 2010. The snoRNA MBII-52 (SNORD 115) is processed into smaller RNAs and regulates alternative splicing. Hum Mol Genet 19: 1153-1164.

Kore AR, Vaish NK, Kutzke U, Eckstein F. 1998. Sequence specificity of the hammerhead ribozyme revisited; the NHH rule. Nucleic Acids Res 26: 4116-4120.

Lewin AS, Drenser KA, Hauswirth WW, Nishikawa S, Yasumura D, Flannery JG, LaVail MM. 1998. Ribozyme rescue of photoreceptor cells in a transgenic rat model of autosomal dominant retinitis pigmentosa. Nat Med 4: 967-971.

Maas S, Rich A. 2000. Changing genetic information through RNA editing. Bioessays 22: 790-802.

Nahkuri S, Taft RJ, Korbie DJ, Mattick JS. 2008. Molecular evolution of the HBII-52 snoRNA cluster. J Mol Biol 381: 810-815.

Nishikura K. 2010. Functions and regulation of RNA editing by ADAR deaminases. Annu Rev Biochem 79: 321-349.

Nurpeisov V, Hurwitz SJ, Sharma PL. 2003. Fluorescent dye terminator sequencing methods for quantitative determination of replication fitness of human immunodeficiency virus type 1 containing the codon 74 and 184 mutations in reverse transcriptase. J Clin Microbiol 41: 3306-3311.

Osenberg S, Paz Yaacov N, Safran M, Moshkovitz S, Shtrichman R, Sherf O, Jacob-Hirsch J, Keshet G, Amariglio N, Itskovitz-Eldor J, et al. 2010. Alu sequences in undifferentiated human embryonic stem cells display high levels of A-to-I RNA editing. PLoS One 5: e11173.

Park E, Williams B, Wold BJ, Mortazavi A. 2012. RNA editing in the human ENCODE RNA-seq data. Genome Res 22: 1626-1633.
Parthasarathy R, Cote GJ, Gagel RF. 1999. Hammerhead ribozymemediated inactivation of mutant RET in medullary thyroid carcinoma. Cancer Res 59: 3911-3914.

Penedo JC, Wilson TJ, Jayasena SD, Khvorova A, Lilley DM. 2004. Folding of the natural hammerhead ribozyme is enhanced by interaction of auxiliary elements. RNA 10: 880-888.

Peng Z, Cheng Y, Tan BC, Kang L, Tian Z, Zhu Y, Zhang W, Liang Y, Hu X, Tan X, et al. 2012. Comprehensive analysis of RNA-Sec data reveals extensive RNA editing in a human transcriptome. Nat Biotechnol 30: 253-260.

Perriman R, Delves A, Gerlach WL. 1992. Extended target-site specificity for a hammerhead ribozyme. Gene 113: 157-163.

Persson T, Hartmann RK, Eckstein F. 2002. Selection of hammerhead ribozyme variants with low $\mathrm{Mg}^{2+}$ requirement: Importance of stem-loop II. Chembiochem 3: 1066-1071.

Prasanth KV, Prasanth SG, Xuan Z, Hearn S, Freier SM, Bennett CF, Zhang MQ, Spector DL. 2005. Regulating gene expression through RNA nuclear retention. Cell 123: 249-263.

Rueter SM, Dawson TR, Emeson RB. 1999. Regulation of alternative splicing by RNA editing. Nature 399: 75-80.

Ruffner DE, Stormo GD, Uhlenbeck OC. 1990. Sequence requirements of the hammerhead RNA self-cleavage reaction. Biochemistry 29: 10695-10702.

Saksmerprome V, Roychowdhury-Saha M, Jayasena S, Khvorova A, Burke DH. 2004. Artificial tertiary motifs stabilize trans-cleaving hammerhead ribozymes under conditions of submillimolar divalent ions and high temperatures. RNA 10: 1916-1924.

Scherr M, Grez M, Ganser A, Engels JW. 1997. Specific hammerhead ribozyme-mediated cleavage of mutant $\mathrm{N}$-ras mRNA in vitro and ex vivo. Oligoribonucleotides as therapeutic agents. J Biol Chem 272: 14304-14313.

Schoft VK, Schopoff S, Jantsch MF. 2007. Regulation of glutamate receptor B pre-mRNA splicing by RNA editing. Nucleic Acids Res 35: 3723-3732.

Sommer B, Kohler M, Sprengel R, Seeburg PH. 1991. RNA editing in brain controls a determinant of ion flow in glutamate-gated channels. Cell 67: 11-19.

Tedeschi L, Lande C, Cecchettini A, Citti L. 2009. Hammerhead ribozymes in therapeutic target discovery and validation. Drug Discov Today 14: 776-783.

Uhlenbeck OC. 1987. A small catalytic oligoribonucleotide. Nature 328: 596-600.

Vazquez-Tello A, Castán P, Moreno R, Smith JM, Berenguer J, Cedergren R. 2002. Efficient trans-cleavage by the Schistosoma mansoni SMal hammerhead ribozyme in the extreme thermophile Thermus thermophilus. Nucleic Acids Res 30: 1606-1612.

Vesely C, Tauber S, Sedlazeck FJ, von Haeseler A, Jantsch MF. 2012. Adenosine deaminases that act on RNA induce reproducible changes in abundance and sequence of embryonic miRNAs. Genome Res 22: $1468-1476$.

Wang Q, Khillan J, Gadue P, Nishikura K. 2000. Requirement of the RNA editing deaminase ADAR1 gene for embryonic erythropoiesis. Science 290: 1765-1768.

Werner M, Uhlenbeck OC. 1995. The effect of base mismatches in the substrate recognition helices of hammerhead ribozymes on binding and catalysis. Nucleic Acids Res 23: 2092-2096.

Werry TD, Loiacono R, Sexton PM, Christopoulos A. 2008. RNA editing of the serotonin $5 \mathrm{HT} 2 \mathrm{C}$ receptor and its effects on cell signalling, pharmacology and brain function. Pharmacol Ther 119: $7-23$.

Yang W, Chendrimada TP, Wang Q, Higuchi M, Seeburg PH, Shiekhattar R, Nishikura K. 2006. Modulation of microRNA processing and expression through RNA editing by ADAR deaminases. Nat Struct Mol Biol 13: 13-21.

Yeo J, Goodman RA, Schirle NT, David SS, Beal PA. 2010. RNA editing changes the lesion specificity for the DNA repair enzyme NEIL1. Proc Natl Acad Sci 107: 20715-20719. 

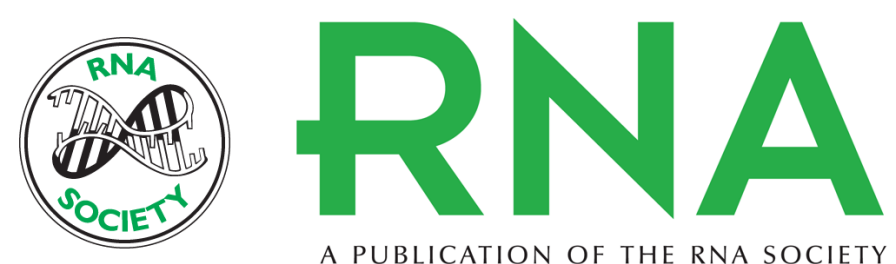

A PUBLICATION OF THE RNA SOCIETY

\section{Improved design of hammerhead ribozyme for selective digestion of target RNA through recognition of site-specific adenosine-to-inosine RNA editing}

Masatora Fukuda, Kei Kurihara, Shota Yamaguchi, et al.

RNA 2014 20: 392-405 originally published online January 21, 2014

Access the most recent version at doi:10.1261/rna.041202.113

Supplemental Material

References

Creative Commons License

Email Alerting Service
http://rnajournal.cshlp.org/content/suppl/2014/01/08/rna.041202.113.DC1

This article cites 57 articles, 16 of which can be accessed free at: http://rnajournal.cshlp.org/content/20/3/392.full.html\#ref-list-1

This article is distributed exclusively by the RNA Society for the first 12 months after the full-issue publication date (see http://rnajournal.cshlp.org/site/misc/terms.xhtml). After 12 months, it is available under a Creative Commons License (Attribution-NonCommercial 3.0 Unported), as described at http://creativecommons.org/licenses/by-nc/3.0/.

Receive free email alerts when new articles cite this article - sign up in the box at the top right corner of the article or click here.

To subscribe to RNA go to:

http://rnajournal.cshlp.org/subscriptions 